\section{THE LUNACY COMMISSIONERS' BLUE BOOKS.}

\section{To the Editor of The Lancet.}

SIr,-In The LanceT of the 28th of April, in a notice of the recent numbers of the Journal of Mental Science (for which I cordially thank you), your reviewer makes one or two remarks on lunacy matters which I ask leave briefly to contrast with the opinions of a writer in the British and Foreign Medico-Chirurgical Review for April, on the "Lunacy Commissioners' Blue Books."

I. The Statistics of Inscuity.-The Lancer and the MedicoChirurgical Review alike condemn the present haphazard manner in which the statistics of our English county asylums are recorded. As you truly remark, these statistics as now framed are idle labour. There is no uniformity between the elaborate tables of different reports; and the tables of the same report fail to give any continuous history of the experience of the asylum, which alone would be of real value: they mostly give only the semblance of information. In similar terms the writer in the Medico-Chirurgical Review speaks of the desultory observations pursued by various asylum officers, each of whom frames his figures in which shape he pleases, and publishes them or not, as fancy leads him.

This evil is, I am glad to say, on the mend. Of the reports already issued this year, several, I find, have adopted the uniform system of tables recommended last July by the committee of the Medico-Psychological Association, and which were favourably noticed at the time in THe LANCET. The Hants County, the Bristol Borough, the Cumberland and Westmoreland County, the Wilts County, the Glamorgan County, and the Sussex County Asylums, have introduced the six statistical tables which were then recommended. I hope others may follow this lead. I was sorry to notice their omission from the otherwise carefully compiled report of the Colney Hatch Asylum. Probably some old resolution of the committee (by which all things are there guided) as yet prevents the free action herein of the medical superintendents.

These tables of the Medico-Psychological Association have also, I believe, been under the consideration of the Commissioners in Lunacy both in England and Scotland; and I have therefore every reason to hope that our uniform system of asylum statistics will ere long prevail

2. The work of the Commissioners in Lunacy.--The writer in Trre LanCET acknowledges the great and beneficial reforms in the treatment of the insane which have resulted from the weight and influence of the Commissioners in Lunacy, and I should have thought that he expressed the unanimous opinion of those engaged in this department of practice. Yet in the Medico-Chirurgical Review I find a very different estimate of the benefit to the insane and of the advancement of the study of mental diseases which have resulted from the unwearying labours-now of nineteen years' duration-of the Commissioners in Lunacy. Thus the writer says :-_"The energies of the Commissioners are benumbed by time ;" "their reports show signs of atrophy;" "their power is asserted in a way little consonant with the feelings of the public :" "their constant aim is to add to their power so as to acquire the right to inquire into somebody's business, or to legalize some vexatious interference "" "all recent lunacy legislation is but a mere collection of devices to overcome some obstacles met with in the would-be triumphant career of these enterprising officials." "To be mad now," he adds, "is to become a patient of the State, and the prescriptions should properly be dated from No. 19, Whitehall-place."

Assuredly the public do not share these opinions of the unnecessarily inquisitorial powers of the Lunacy Commissioners. The tendency of all recent lunacy legislation has been, on the motion of independent members of the House of Commons, to extend the jurisdiction and to add to the authority of the Lunacy Board. Only the other day it was proposed, with the apparent approval of the House, that this Board should be officially represented in the Commons by one of its members. And in every lunacy scandal or trial (and which unfortunately is much the same thing) the demand is always for further action on the part of the Government officials in lunacy.

It is to be regretted that such opinions should have found so honourable a place as the pages of the Medico-Chirurgical Review. I am old enough to recall the asylums, public and private, of twenty years ago, and the position which their medical officers held, and strange, beyond belief almost, is the contrast with those of to-day. The public asylums then were little more than dismal houses of detention. The comforts of the patients were few, the means of curative treatment less; the medical officers were ill paid and slightly esteemed, and their authority subordinate or divided with other officials. Of the private asylums then the less said the better. The pauper licensed houses of twenty years ago were mysteries of abomination. Even the first-class private asylums were mean and miserable to a degree. A resident medical officer was then the exception there. How the Commissioners have fought, step by step, the upward battle of reform the limits of this communication entirely prevent my tracing. Should you allow me, I shall some day send you a sketch of this progress, which the writer in the Medico-Chirurgical Review seems so entirely to have forgotten. I can only here, in conclusion, notice the reviewer's picture of the present state of things. "The oppressive tyranny of the Commissioners" has, he says, as regards private asylums, " effectually extinguished all opposition," and " proprietors, however conscientious and upright, are compelled in self-defence to defer to the powers that be." I am only familiarly acquainted with two private asylums-viz., those of Dr. Newington, at Ticehurst, and of Dr. Harrington Tuke, at Chiswick. As regards the position or feelings of these gentlemen towards the Lunacy Board, I can most positively say that the reviewer misrepresents them.

His exposition of the present relations of the Commissioners to the public asylums is still more untrue. "As regards the rulers of public asylums," he writes, "the case is not very different; for though country gentlemen do not always find the yoke easy, they too often, conscious of their ignorance, accept the dictum of a body who are always ready to suggest, and if their advice is not taken can embarrass a committee by persevering opposition, and threaten them with the terrors of the Secretary of State."

I can here speak with more authority. I am in intimate relations with the most distinguished superintendents of our public asylums, and I say, without fear of contradiction, that this view of our position towards the Commissioners is ab. surdly false. Support, not embarrassment, is what we receive at their hands. The unvarying tradition of the Board has been to bring into prominence and in every way to exalt the position of the medical superintendent; and it is to these efforts that our position of independent authority in the asylum and of influence with the Committee of Visitors is mainly due. I am sure that every county asylum superintendent will endorse this opinion. Then, as to the tyranny of the Commissioners over the Committee of Visitors, the thing is a stupid fiction, which no one acquainted with the independent character of the English magistracy will accept. The influence of the Commissioners on the counsels of the Visitors is due alone to the value of their suggestions, the acceptance of which, indeed, is solely at the pleasure of the justices, who are therein much influenced by the opinions of their medical superintendent. To him the suggestions of the Commissioners. are a source of strength and aid.

3. Lastly, the reviewer turns with prophetic eye to the future, and sees "signs of an approaching reaction," when the cost of maintenance in the public asylums-" maintained at the highest by an extravagance for which the Commissioners are in a great measure responsible"--shall be reduced by a curtailment of the " expensive follies in which many of them abound," and, above all, by the substitution of a plan of farming out the insane paupers-the insane in private dwellings -for the present asylum arrangements. I cannot at the end of a long letter venture to open up these questions. I would only say that the reviewer is mistaken in his assertion that " the English asylum system is now openly challenged-nay, even deprecated-by the Scotch Commissioners." A deputyinspector of that Board, who never had any experience of the practical treatment of the insane, indulges, $I$ am aware, in such high-flown theories; but the Lunacy Board in Scotland have never given their official sanction to them. I would here refer to an able paper, "Gheel in the North," in the Journa" of Mental Science for July, 1865, in support of my assertion. In the pages of the same journal for January and April, 1865 , will also be found two papers on "The Means of Extending the Public Asylum System," in which I have already discussed Dr. Mitchell's views again here brought out by this writer in the Medico-Chirurgical Review.

I am, Sir, your obedient servant, C. L. Robertson, M.D.

Hayward's Heath, Sussex, May 8th, 1866. 